\title{
Effects of remote and local atmospheric forcing on circulation and upwelling in the Baltic Sea
}

\author{
By A. LEHMANN*, W. KRAUSS and H.-H. HINRICHSEN, Institute of Marine Research, \\ Düsternbrooker Weg 20, 24105 Kiel, Germany
}

(Manuscript received 5 February 2001; in final form 4 December 2001)

\begin{abstract}
Due to the ephemeral nature of the atmospheric conditions over the Baltic Sea, the flow field is highly variable, and thus, changes in the resulting circulation and upwelling are difficult to observe. However, three-dimensional models, forced by realistic atmospheric conditions and river runoff, have reached such a state of accuracy that the highly fluctuating current field and the associated evolution of the temperature and salinity field can be described. In this work, effects of remote and local atmospheric forcing on circulation and upwelling in the Baltic Sea are investigated. Changes in the characteristics of the large-scale atmospheric wind field over the central and eastern North Atlantic can be described by the North Atlantic Oscillation (NAO). The NAO is related to the strength and geographical position of weather systems as they cross the North Atlantic and thus has a direct impact on the climate in Europe. To relate the local wind field over the Baltic Sea to the large-scale atmospheric circulation, we defined a Baltic Sea Index (BSI), which is the difference of normalised sea level pressures between Oslo in Norway and Szczecin in Poland. The NAO is significantly related to the BSI. Furthermore, the BSI is highly correlated with the storage variation of the Baltic Sea and the volume exchange through the Danish Sounds. Based on three-dimensional model calculations, it is shown that different phases of the NAO during winter result in major changes of horizontal transports in the deep basins of the Baltic Sea and in upwelling along the coasts as well as in the interior of the basins. During $\mathrm{NAO}^{+}$phases, strong Ekman currents are produced with increased up- and downwelling along the coasts and associated coastal jets, whereas during $\mathrm{NAO}^{-}$phases, Ekman drift and upwelling are strongly reduced, and the flow field can almost entirely be described by the barotropic stream function. The general nature of the mean circulation in the deep basins of the Baltic Sea, obtained from a 10-yr model run, can be described by the depth integrated vorticity balance derived from the transport equation for variable depth.
\end{abstract}

\section{Introduction}

On the long-term mean, the water balance of the Baltic Sea is controlled by in- and outflows through the entrance area, river runoff and the net precipitation (precipitation minus evaporation). Due to the freshwater surplus, in the upper layer a general outflow of brackish Baltic Sea water is forced. This is compensated by a deep

\footnotetext{
* Corresponding author. e-mail: alehmann@ifm.uni-kiel.de
}

inflow of saline water from the Kattegat. The mean conditions are superimposed by fluctuating in- and outflow phases, forced by variable atmospheric conditions which cause out of phase variations of sea levels in the Baltic Sea and the Kattegat. The resulting barotropic flow will alter direction as the sea level of the Kattegat varies with air pressure and wind set-up (e.g. Jacobsen, 1981; HELCOM, 1986; Stigebrandt, 1983). Among others, Dietrich (1951) was already able to relate the surface currents in the Danish Sounds to the local wind conditions. He stated that westerly 
winds with speeds between $2-5 \mathrm{~m} \mathrm{~s}^{-1}$ are necessary to stop the general outflow of brackish Baltic Sea water. Thus, smoothly increasing westerly winds will stop the general outflow, and due to the freshwater surplus, the water volume in the Baltic Sea will increase, although no direct inflow is forced. A review of the current knowledge of the dynamics of the water exchange between the Baltic Sea and the North Sea has been given by Gustafsson (1997). The important role of storage variations in water balance studies of the Baltic Sea has been discussed in Lehmann and Hinrichsen (2001).

The relation between major Baltic inflows and large-scale atmospheric circulation patterns has been investigated by Matthäus and Schinke (1994) and Schinke and Matthäus (1998). Strong inflow is mainly caused by persistent, i.e. of a duration of several weeks, strong westerly winds over the eastern North Atlantic and northern Europe.

A measure of the strength of the zonal wind field over the central and eastern North Atlantic is the North Atlantic Oscillation (NAO), which is a phenomenon responsible for climate variability in Europe. Positive values of the NAO index indicate stronger-than-average westerlies over the mid-latitudes, associated with low-pressure anomalies over the region of the Iceland low- and anomalously high-pressure across the subtropical Atlantic. For the low-pass filtered NAO winter index, it appears that since 1980 the NAO index has remained in a highly positive phase, with the winters of 1983, 1989 and 1990 marked by the highest positive values of the NAO index recorded since 1864 (Hurrell and van Loon, 1997).

The NAO is related to the strength and geographical position of weather systems as they cross the North Atlantic, which in turn determine precipitation (Hurrell, 1995) and sea surface temperature (Planque and Taylor, 1998). The NAO is also likely to have an impact on the direction and magnitude of currents, the height of waves, wind mixing and the stability of the water column.

For the Baltic Sea, the influence of the NAO on the sea ice conditions has been reported by Koslowsky and Loewe (1994) and Koslowsky and Glaser (1999). Statistically significant relations between the ice extent of the Baltic Sea, changes in air temperature and the large-scale atmospheric circulation have been described by Omstedt and Chen (2001). Hänninen et al. (2000) investigated the Atlantic control on oceanographic and ecological changes in the Baltic Sea. They found evidence for a general chain-of-events relationship between the NAO and the freshwater runoff to the Baltic Sea, and also to the deep water salinity in the Gotland Basin. A further study of the dependence of salinity and oxygen concentrations in the Baltic Sea on the large-scale atmospheric circulation has been presented by Zorita and Laine (2000). They found that a stronger meridional sea level pressure gradient over the North Atlantic caused positive rainfall anomalies and increased runoff, giving rise to decreased salinities at all depths. Due to the weakened stratification or stronger or more frequent inflows, deep water oxygen concentrations were enhanced.

Changes in runoff and net precipitation certainly have an influence on the circulation of the Baltic Sea and the water mass exchange with the North Sea. However, in this paper we concentrate on changes of circulation patterns on a monthly time scale, which are directly forced by changes in the large-scale atmospheric circulation.

From long-term current observations at different positions, the general circulation of the Baltic Sea can be derived. However, due to enormous costs and extensive fishing activities which make it impossible, at least in some areas of the Baltic Sea, to install corresponding observational systems, it is not possible to measure the general circulation. Although surface currents have been obtained from different locations in the Baltic Sea (Sjöberg, 1992), the three-dimensional structure and the variability of the circulation are more or less unknown. Even in the mid-seventies, Dietrich and Schott (1974) were only able to summarize the knowledge of the mean circulation of the Baltic Sea by the statement that it is weak and in counter-clockwise direction (see also Sjöberg, 1992). The relationship between the weak mean surface circulation and the long-term salinity gradient in the Baltic Sea has been pointed out by Kullenberg (1981). The spreading of juvenile freshwater, apparent in the seasonal salinity variation of the surface layer (Gustafsson and Stigebrandt, 1996) which is also associated with the surface circulation, has been investigated by Eilola and Stigebrandt (1998). They pointed out that the correct simulation of the spreading of juvenile freshwater and the corresponding surface salinity evolution provide a challenging test case for 
three-dimensional state-of-the-art hydrodyamical ocean circulation models.

In the last few years, three-dimensional numerical models with high vertical and horizontal resolution have become available for the Baltic Sea. Thus, a detailed view of the three-dimensional current field and the barotropic circulation of the entire Baltic Sea in dependence on the atmospheric conditions and river runoff could be described (Lehmann, 1995; Elken, 1996; Schrum and Backhaus, 1999; Lehmann and Hinrichsen 2000a, Lehmann and Hinrichsen, 2000b; Meier, 1999). However, it should be noted that diagnostic calculations and idealized simulations of the circulation of the Baltic Sea have been performed earlier by Sarkisyan et al. (1975), Simons (1978) and Kielmann (1981).

The purpose of this paper is to study the variations of horizontal transport and upwelling in the Baltic Sea in response to changes in remote and local atmospheric forcing conditions. Basinwide observations of currents and upwelling in the Baltic Sea are not available, but threedimensional models of the Baltic Sea have reached a state of accuracy that reliable answers can be given. A 10-yr simulation with a coupled sea iceocean model forms the basis of a statistical analysis of the correlation between remote and local atmospheric forcing and the response of the Baltic Sea. Two different winter periods from December to March, where the NAO has a local maximum and minimum, respectively, are analysed with respect to changes in the circulation and upwelling, and compared with the general circulation derived from a long-term average.

\section{Baltic Sea model and data}

The coupled sea ice-ocean model of the Baltic Sea, used in this study, is based on the BryanCox-Semtner general circulation model with a free surface (Killworth et al., 1991). The model is based on primitive equations derived from the Navier-Stokes equations, applying the shallow water, the traditional and the hydrostatic approximation. The conservation equations for momentum, temperature and salinity, along with their boundary conditions, are solved on a staggered Arakawa B-grid using a finite difference technique. For the advection of momentum and tracers, central differences are applied. For turbulence closure, a $k-\varepsilon$ model has been implemented (e.g. Meier, 2000). The general ocean circulation model has been adapted to the Baltic Sea (Lehmann, 1995), and coupled to a dynamicthermodynamic sea ice model (Stössel and Owens, 1992; Harder, 1996; Lehmann and Hinrichsen, 2000a). Sea ice dynamics are described by a viscous-plastic rheology (Hibler, 1979), and the thermodynamical ice growth rates are derived from the surface energy balance following Parkinson and Washington (1979), using the Semtner zero-layer approach. The horizontal resolution of the coupled sea ice-ocean model is $5 \mathrm{~km}$ (eddy-permitting), and in the vertical 41 levels are specified, which enables us to resolve the upper $100 \mathrm{~m}$ with levels of $3 \mathrm{~m}$ thickness. The model domain and bottom topogaphy are displayed in Fig. 1. At the western boundary, a simplified North Sea is connected to the Skagerrak in order to provide characteristic North Sea water masses in case of inflow conditions, and to take up sea level elevations due to different forcing conditions

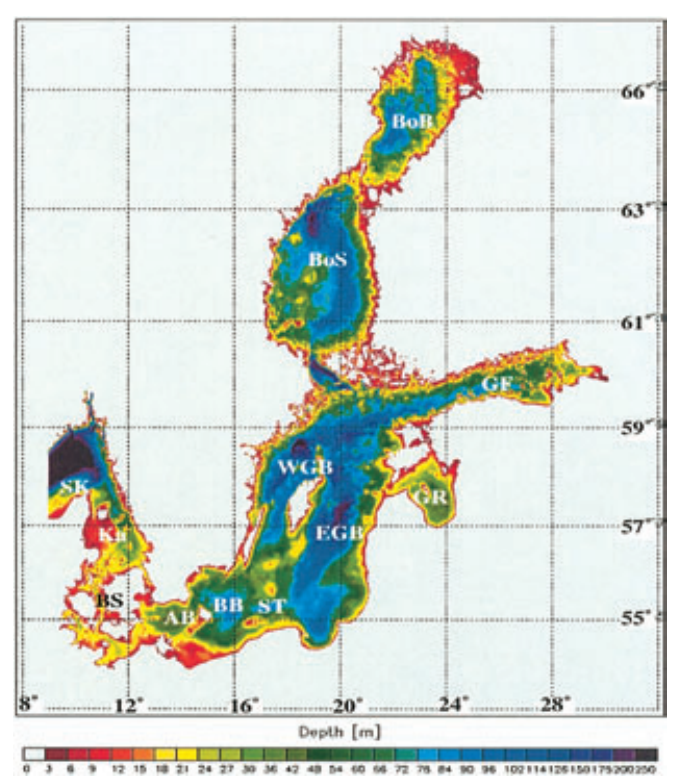

Fig. 1. Model domain and bottom topography of the Baltic Sea. SK, Skagerrak; Ka, Kattegat; BS, Belt Sea (Danish Sounds); AB, Arkona Basin; BB, Bornholm Basin; ST, Stolpe Trench; EGB, Eastern Gotland Basin; WGB, Western Gotland Basin; GR, Gulf of Riga; GF, Gulf of Finland; BoS, Bothnian Sea; BoB, Bothnian Bay. 
(Lehmann, 1995). At the western boundary of the simplified North Sea $\left(4^{\circ} \mathrm{E}\right)$, the sea level is adjusted to a constant reference value, which has been determined from the sea level inclination calculated from the initial density distribution. With respect to the reference level, volume is supplied/ extracted from the North Sea in case of in/outflow conditions. The salinity in the North Sea basin is relaxed to a climatology. Thus, sea level changes in the Skagerrak are determined by the atmospheric forcing acting on the total model domain including the area of the simplified North Sea, and river runoff supplied to the Baltic Sea and the Kattegat. Sea level changes, propagating into the North Sea from the Atlantic, and tides are not considered. For a perfect simulation of the sea level changes in the Skagerrak/Kattegat, the whole area of the North Sea has to be taken into acount, with additional boundary conditions for the transitions to the North Atlantic and the English Channel. The baroclinic mode and the tracer equations are stepped forward in time with a leapfrog timestep (300 s). For the barotropic mode, an Euler backward scheme is used (30 s). A detailed description of the finite difference formulation can be found in Killworth et al. (1989).

The model has been proven to be suitable to simulate the major features of the Baltic Sea. These include the general circulation, thermal and haline stratification, major Baltic inflows as well as the general water mass exchange with the North Sea and within the deep basins of the Baltic Sea (Lehmann, 1995; Hagedorn et al., 2000; Lehmann and Hinrichsen, 2000a; Lehmann and Hinrichsen, 2000b). The model has also been applied to explain variabilities in Baltic cod recruitment processes (Hinrichsen et al., 1997; Voss et al., 1999; Hinrichsen et al., 2001a,b).

The coupled sea ice-ocean model is forced by realistic atmospheric conditions taken from the SMHI (Swedish Meteorological and Hydrological Institute, Norrköping, Sweden) meteorological data base (Larss Meuller, personal communication) which covers the whole Baltic drainage basin on a regular grid of $1 \times 1^{\circ}$, with a temporal increment of $3 \mathrm{~h}$. The database includes: geostrophic wind, 2-m air temperature, 2-m relative humidity, surface pressure, cloudiness and precipitation. Additionally, river runoff has been prescribed from a monthly mean runoff data set (Bergström and Carlsson, 1984). Prognostic vari- ables of the coupled sea ice-ocean model are: sea ice thickness and compactness, sea ice drift, the oceanic baroclinic current field, the threedimensional temperature, salinity and oxygen distributions, the two-dimensional surface elevation and the barotropic transport. These prognostic variables have been extracted from the model every $6 \mathrm{~h}$ and form the database for the subsequent analysis. The model has been run for two periods, the first extending over a 4-yr period starting in January 1992 and the second over a 10-yr period starting in January 1986. From the 4-yr run, Lehmann and Hinrichsen (2000b) calculated the general circulation of the Baltic Sea.

\section{The influence of the North Atlantic Oscillation on the water volume exchange}

The NAO is a large-scale atmospheric pattern which influences the climate in Europe (Hurrell, 1995; Osborn et al., 1999). This is especially true under high $\mathrm{NAO}^{+}$conditions, where the spatial correlation length is extended to northern Europe. Changes in the mean atmospheric circulation patterns over the North Atlantic are accompanied by pronounced shifts in storm tracks and associated synoptic eddy activity, i.e. enhanced variance over the North Atlantic and northern Europe and reduced storm track activity over the subtropical Atlantic (Hurrell and van Loon, 1997). Under low $\mathrm{NAO}^{+}$or $\mathrm{NAO}^{-}$conditions, the spatial correlation length scale decreases, and the influence of the westerlies on northern Europe becomes small, so that the continental influence on the climate increases (Hurrell, 1995). However, the weakened influence of the westerlies for northern Europe is a precondition of outflow for the Baltic Sea. Thus, $\mathrm{NAO}^{-}$phases also have the potential to indirectly affect the circulation in the Baltic Sea and the water mass exchange with the North Sea.

A recent investigation of the link between the NAO and the Arctic ice export (Hilmer and Jung, 2000) revealed an eastward shift in the position of the NAO's centers of interannual variability during the last two decades. This shift was accompanied by a relatively strong increase of the NAO during the last three decades (Hurrell, 1995). It is interesting to note that since the end of the 1970s, the frequency of major Baltic inflows which are important for the renewal of the bottom water in 
the Baltic Sea deep basins decreased drastically (Matthäus and Schinke, 1994). Lass and Matthäus (1996) contributed the lack of major inflows between 1976 and the end of 1992 to changes in the wind field over the North and Baltic Sea.

The NAO index, used here (Fig. 2), is defined as the difference between the normalised sea level pressure (SLP) anomalies between the Azores and Iceland (Rogers, 1984). The SLP anomalies at each station were normalised by dividing each pressure by the long-term mean (1865-1997) standard deviation. The NAO winter index is defined by the average over the period of December, January, February and March (Hurrell, 1996). In Fig. 2 the monthly NAO index and winter NAO index are displayed only for the period from 1979 to 1998, which coincides with the period where atmospheric forcing data (SMHI Meteorological data base, 1979-1998) are available. The variability of the NAO on a monthly scale is rather high, and changes from high $\mathrm{NAO}^{+}$ to low $\mathrm{NAO}^{-}$phases can happen during a onemonth period.

\section{Baltic Sea Index (BSI) and model performance}

With respect to the local atmospheric wind conditions over the western Baltic Sea, we defined a Baltic Sea Index (hereafter BSI) as the difference of normalised SLP anomalies at the positions of $53^{\circ} \mathrm{N} 30^{\prime}, 14^{\circ} \mathrm{E} 30^{\prime}$ and $59^{\circ} \mathrm{N} 30^{\prime}, 10^{\circ} \mathrm{E} 30^{\prime}$, about Szczecin (Poland)-Oslo (Norway). SLPs have been obtained from the SMHI Meteorological data bank (Lars Meuller, personal communication) in which SLPs are stored every $3 \mathrm{~h}$. By analogy with the definition of the NAO index, SLP anomalies at each position were normalised by dividing each SLP by the long-term mean (1979-1998) standard deviation. Monthly mean SLP differences (BSI) are displayed in Fig. 2 for the period 1979-1998. From previous studies, it is to be expected that sea level pressure differences between the two sites, with a north-south distance of approximately $600 \mathrm{~km}$, show a high correlation with volume changes of the Baltic Sea. Furthermore, the water mass exchange with the North Sea through the Danish Sounds is strongly controlled by the sea surface inclination between the Kattegat and the western Baltic Sea, which in turn is a direct consequence of the prevailing atmospheric conditions (e.g. Stigebrandt, 1983; Lass and Schwabe, 1990; Matthäus and Schinke, 1994). A positive BSI corresponds to an anomalous SLP difference, with westerly winds over the Skagerrak/Kattegat and the western Baltic which pile up water in the Kattegat and lower the sea level in the western Baltic Sea, leading to inflow

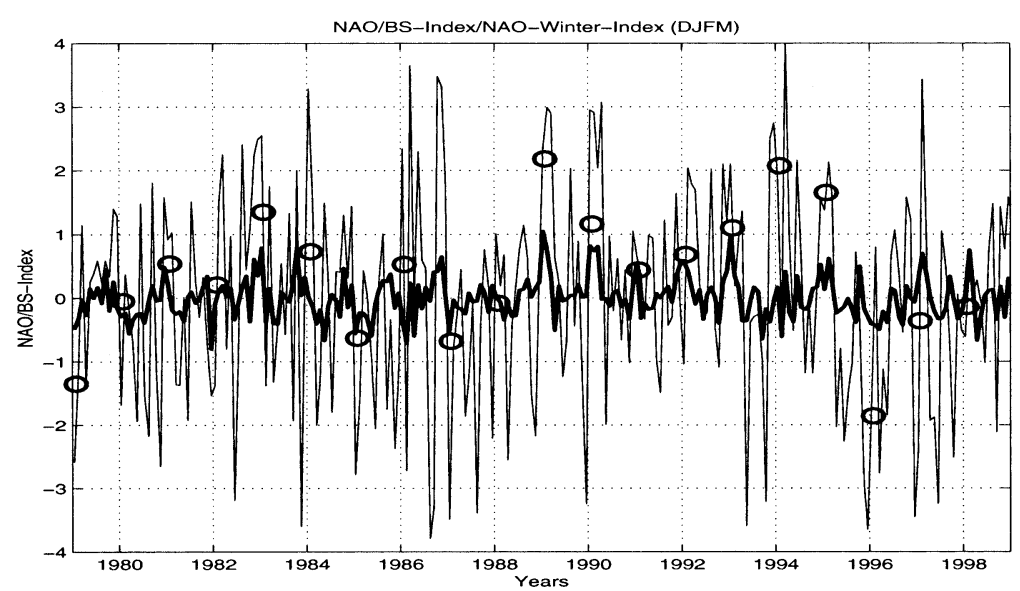

Fig. 2. Monthly NAO Index for 1979-1998 (thin line), defined as the difference of normalised SLP anomalies at Azores and Island. SLPs have been normalised by dividing each pressure by the long-term mean (1863-1999) standard deviation. Circles represent the NAO winter (DJFM) index and the bold line represents the monthly BSIs for the years 1979-1999.

Tellus 54A (2002), 3 
conditions. A negative BSI corresponds to easterly winds, favouring outflow conditions.

To visualise the teleconnection of typical high $\mathrm{NAO}^{+}$and low $\mathrm{NAO}^{-}$phases to the Baltic Sea catchment area, we calculated ensemble averages of SLP anomalies from the NCEP/NCAR re-analysis data (1948-1999; Kalnay et al., 1996) for January, February and March (JFM) within the period from 1979 to 1998. The criterion for choosing specific years to contribute to the ensemble is that the three-month average of the $\mathrm{NAO}$ indices remains positive or negative. The ensemble for the $\mathrm{NAO}^{-}$phase consists of the years $1979(-0.76), 1985(-1.29), 1987(-1.41)$ and $1996(-1.08)$, and for the $\mathrm{NAO}^{+}$phase of the years 1989 (2.72), 1990 (2.56), 1992 (1.17), 1993 (1.71) and 1995 (1.72). For the chosen years, the corresponding BSI also remains positive or negative (Fig. 2). Although in JFM 1993 the latest major Baltic inflow has happened, the three-month average of NAO indices ranks only as number 4 in the JFM ensemble (rank 3 for BSIs; cf. also Fig. 4). Obviously, strong westerly winds are not the only precondition for a major Baltic inflow to happen. Furthermore, the winter of 1996 ranks only at number 3 of the NAO JFM ensemble, but on rank 1 if the BSI is considered. This indicates that for a classification of the atmospheric conditions over the western Baltic Sea, a local index is more appropriate. The ensemble averages for the different NAO phases (Fig. 3) reveal an increased SLP gradient over the North Atlantic and Baltic Sea for $\mathrm{NAO}^{+}$and a corresponding weakened SLP gradient for $\mathrm{NAO}^{-}$, again extending far into the Baltic area.

The volume change of the Baltic Sea is reflected in the mean sea level changes of the Baltic Sea, which can be represented by the sea level at Landsort (Lisitzin, 1974; Jacobsen, 1981). This relation can be used as an independent check of the performance of the numerical model. The volume change $(\Delta V)$ can be described by the volume balance equation

$A \frac{\partial \eta}{\partial t}=\Delta V=Q_{\mathrm{i} / \mathrm{o}}+(P-E) A+R$

where $A$ denotes the surface area of the Baltic Sea, $\eta$ the mean sea level, $Q_{\mathrm{i} / \mathrm{o}}$ in- and outflow through the Danish Sounds, $P$ and $E$ represent precipitation and evaporation rates and $R$ the river runoff. $Q_{\mathrm{i} / \mathrm{o}}$ comprises the flow forced by the freshwater surplus

$R+(P-E) A \sim 17,000 \mathrm{~m}^{3} \mathrm{~s}^{-1}$,

Omstedt et al., 1997, and a highly fluctuating flow driven by the instantaneous sea level difference between the Kattegat and the western Baltic Sea. For the long-term mean, it is reasonable to assume

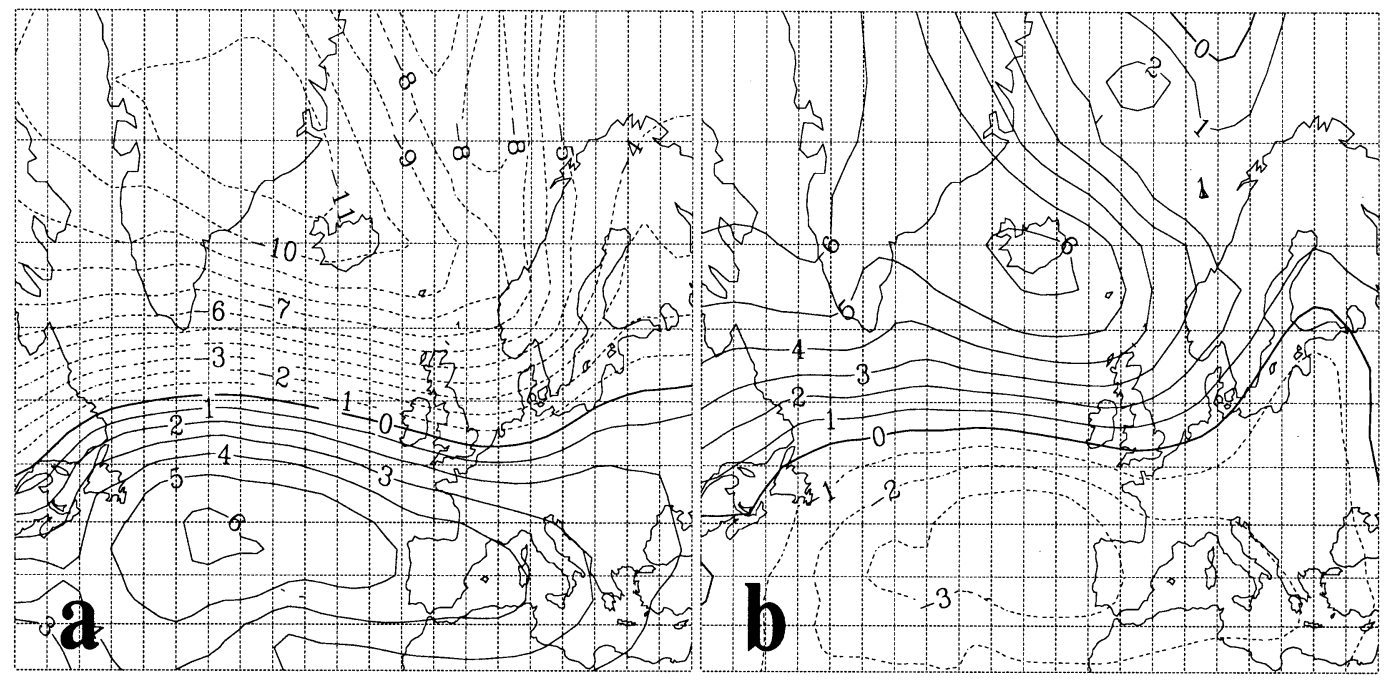

Fig. 3. Ensemble average of sea level pressure anomalies (hPa) for (a) $\mathrm{NAO}^{+} \mathrm{JFM}^{(1989,1990,1992,1993,1995)}$ and (b) NAO- JFM $(1979,1985,1987,1996)$. Contour interval is $1 \mathrm{hPa}$. 
that the volume change $(\Delta V)$ is zero, and the freshwater surplus is balanced by the outflow. Thus, the highly fluctuating in- and outflow, forced by the sea level inclination between the Kattegat and the western Baltic Sea, is mainly responsible for the volume change on a weekly timescale. We detrended the integrated net flow through the Danish Sounds to obtain the part of the flow that is forced by air pressure and wind set-up. The detrended integrated net flow through the Danish Sounds must be directly associated with the volume change of the Baltic Sea. For comparison, weekly averages of the BSI, detrended net flow through the Danish Sounds (VEC) obtained from coupled sea ice-ocean simulations, and sea surface elevations at Landsort (SSE) for the years 1986-1995 are displayed in Fig. 4. Note that during the $10-y r$ period several in- and outflow events occurred which last typically about $40 \mathrm{~d}$. Storage variations of characteristically $100 \mathrm{~km}^{3}$ with a period of about 1 month were also recognized by Jacobsen (19981) and Lass and Schwabe (1990). In a study of the main characteristics of the long-term sea level variability in the Baltic Sea, Samuelsson and Stigebrandt (1996) attributed sea level changes of periods longer than about one month to externally forced sea level oscillations, driven by the sea level difference between the Kattegat and the western Baltic Sea. They concluded that for sea level oscillations with a period of $>1$ month, the Baltic Sea behaves like an externally forced oscillator, with the oscillations excited by the sea level changes in the Kattegat. Thus, storage variations in the Baltic Sea are due to a corresponding water mass exchange through the Danish Sounds. During the 10-yr period, several inflow events with volume changes $>150 \mathrm{~km}^{3}$ occurred $(1986,1989,1990,1992,1994$, $1995)$ which were not classified as major inflows (Schinke and Matthäus, 1998). Thus, even in the stagnation period strong inflows have happened, but the corresponding salt flux into the Baltic Sea was smaller compared to major inflows.

The correlation coefficients between the BSI, the detrended net flow through the Danish Sounds (VEC) and the sea surface elevations (SSE) are given in Table 1. It is important to note that the correlation between the simulated volume exchange through the Danish Sounds and the sea

Table 1. Correlation coefficients weekly/monthly

\begin{tabular}{lccc}
\hline & $\begin{array}{c}\mathrm{VEC}^{\mathrm{b})} \\
\text { simulated }\end{array}$ & $\begin{array}{c}\mathrm{SSE}^{\mathrm{c}} \\
\text { simulated. }\end{array}$ & $\begin{array}{c}\mathrm{SSE}^{\mathrm{c})} \\
\text { observed }\end{array}$ \\
\hline $\mathrm{BSI}^{\mathrm{a})}$ & $0.60 / 0.68$ & $0.61 / 0.70$ & $0.67 / 0.77$ \\
$\mathrm{VEC}_{\mathrm{b})}$ simulated & $0.90 / 0.88$ & $0.73 / 0.70$ & \\
$\mathrm{SSE}^{\mathrm{b})}$ simulated & & & $0.83 / 0.82$ \\
\hline
\end{tabular}

a) BSI, Baltic Sea Index.

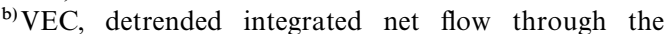
Danish Sounds.

${ }^{c)}$ SSE, Sea surface elevation at Landsort.

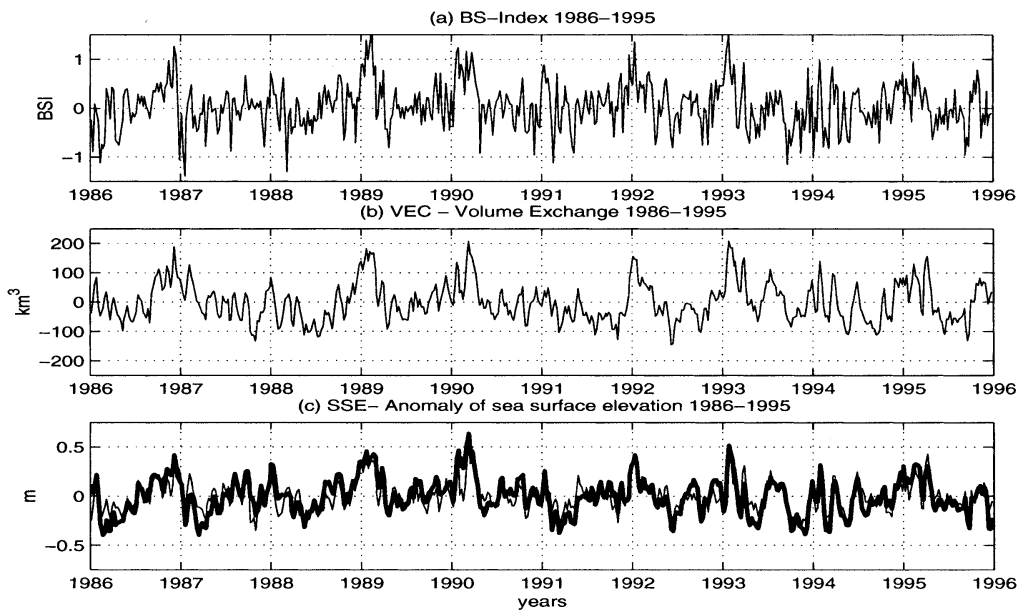

Fig. 4. Weekly averages of (a) the BSI, (b) detrended integrated net flow through the Danish Sounds $\left(\mathrm{km}^{3}\right)$, and (c) anomaly of the sea surface elevation at Landsort (simulated: full line, observed: thin line) for the years 1986-1995. 
level elevation is almost perfect, confirming the Landsort tide gauge to be representative of the water storage in the Baltic Sea. Further, the correlation between the BSI and the observed sea level elevation at Landsort (weekly: $r=0.67$, monthly $r=0.77$, statistically significant at the $95 \%$ level according to the Student's $t$-test) accounts for about $50 \%$ of the variability of the water storage in the Baltic Sea. Long-term records of SLPs and sea level elevations at Landsort can be used to investigate long-term changes in the water storage of the Baltic Sea due to changes in the atmospheric conditions. Furthermore, sea level elevations at Landsort are highly correlated with the detrended integrated net flow through the Danish Sounds. Thus, the model performs well in capturing most of the in -and outflow events happening during a $10-y r$ period.

A further discussion on the model performance with respect to simulating realistic circulations and corresponding salinity structures will be given in Section 6.

\section{Relations between NAO, BSI and volume exchange of the Baltic Sea}

To show that the local atmospheric conditions are correlated with the NAO, we calculated the correlation between the NAO index and the BSI for the period 1979-1998. The linear correlation coefficient is $r=0.5(r=0.68$ for the winter index $)$. The NAO index accounts for $25 \%$ of the variance of the sea level pressure anomaly over the western Baltic, i.e. the large-scale atmospheric patterns have a clear impact on the local atmospheric conditions. The reasons for the correlation coefficient not exceeding 0.5 are mainly as follows: (1) As mentioned in Section 3, under low $\mathrm{NAO}^{+}$ and $\mathrm{NAO}^{-}$conditions the spatial correlation length scale decreases. This occurs mainly during summer months when the influence of the NAO on the Baltic Sea is reduced. (2) The BSI represents the meridional air pressure gradient over a distance of about $600 \mathrm{~km}$, whereas the NAO is based on a distance of about $3000 \mathrm{~km}$. Thus, the BSI includes the gradients of synoptic-scale air pressure variability which are not included in the NAO. This is confirmed by the correlation of the NAO with the local synoptic SLP variability (2-8 d timescale) presented in Osborn et al. (1999).
For the Baltic Sea area, the correlation coefficient was found to be in the range $0.3-0.6$.

The linear correlation between the volume exchange of the Baltic Sea and the NAO index is only $r=0.28(r=0.49$ for the winter index DJFM $)$. Although the correlation of the monthly values is relatively weak, there is a clear tendency which is confirmed by the correlation of the winter index: If the NAO is in a high positive phase, there is a volume increase (inflow) of the Baltic Sea; a negative NAO favours outflow conditions. If we consider only the period from 1989 to 1995, where the NAO winter index remained in a positive phase, then the correlation coefficient increases to 0.35 . Thus, the linear correlation analysis reveals that the NAO accounts for about $10 \%$ of the variance of the general volume exchange of the Baltic Sea with the North Sea.

The correlation of the detrended net flow through the Danish Sounds (VEC) with the BSI is $r=0.68$ ( $r=0.89$ for the winter index). Thus, the atmospheric forcing expressed by the BSI strongly controls the volume exchange with the North Sea. It should be noted that the highest correlation between the volume change and the BSI was obtained if the BSI was lagged by one week, which accounts for a temporal lag between the BSI and sea level changes of the Baltic Sea. Further, if the averaging interval was decreased (sampling interval $\leqslant 5 \mathrm{~d}$ ), the correlation also decreased. Thus, the volume change of the Baltic Sea is mostly driven by the low-scale variability which indeed is correlated with the large-scale atmospheric pattern. It is therefore not surprising that the correlation between NAO index and simulated volume exchange of the Baltic Sea is less than the correlation between BSI and volume exchange.

\section{Wind-driven and mean circulation}

The mean circulation of the entire Baltic Sea has been determined from model simulations for a 4-yr period by Lehmann and Hinrichsen (2000b). They showed from averaged model results that in spite of the ephemeral nature of the atmospheric conditions over the Baltic Sea, persistent circulation patterns (cyclonic circulation cells) result, which comprise mostly the sub-basins of the Baltic Sea with less transport between them. For the 
vertical circulation, two regimes could be identified, one under the direct influence of the wind, comprising the surface layers with up- and downwelling along the coasts, and the other emerging from the cyclonic circulation cells within the deep basins, leading to a broad diapycnal exchange mostly concentrated in the centre of the basins. A qualitative comparison of the simulated circulation with observations, compiled by Sjöberg (1992), has been performed in Lehmann and Hinrichsen (2000a).

In Fig. 5, the transport stream function derived form a 10-yr model simulation is displayed. The 10 -yr average shows only minor differences compared to the 4-yr mean. The transport stream function can be compared with the results from diagnostic computations of the summer circulation of the Baltic Sea presented by Sarkisyan et al. (1975). In the central part of the Baltic Sea, a large cyclonic gyre with a magnitude of $7 \times 10^{4} \mathrm{~m}^{3} \mathrm{~s}^{-1}$ centered in the region of the Gotland Deep was found. Anticyclonic gyres prevailed in the Bornholm Basin, the Gdansk Basin and north of the Gotland Basin, with a magnitude of $(6-7) \times 10^{4} \mathrm{~m}^{3} \mathrm{~s}^{-1}$. Sarkisyan et al. (1975) stated that the main factor in the formation of the circulation is the interaction between bottom topography and buoyancy. Similar circulation patterns have been obtained from the averaged barotropic circulation, displayed in Fig. 5. However, the magnitude of the cyclonic circulation comprising the Gotland Basin $\left(14 \times 10^{4} \mathrm{~m}^{3} \mathrm{~s}^{-1}\right)$ and the area around the Gotland Deep $\left(36 \times 10^{4} \mathrm{~m}^{3} \mathrm{~s}^{-1}\right)$ is considerably higher. This is not suprising, since in our prognostic simulation the horizontal resolution as well as the vertical resolution are considerably increased, which leads to a better representation of the baroclinic gradients as well as the bottom slope, and the simulation spans a full 10-yr period with fluctuating winds and changing baroclinic conditions.

Eilola and Stigebrandt (1998) pointed out that mean salinity distributions could be used for testing dispersion properties of three-dimensional ocean circulation models. In Fig. 6, the 10-yr averaged surface salinity (also averaged vertically

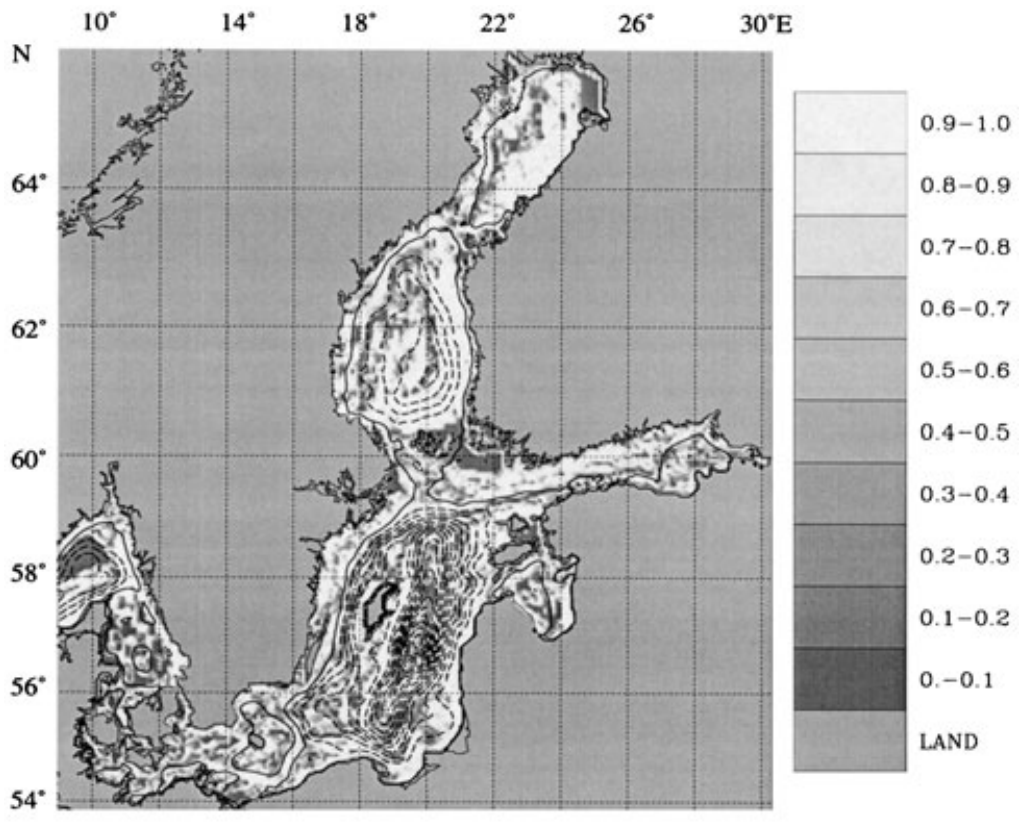

Fig. 5. Stream function representation of the 10-yr averaged 1986-1995 barotropic circulation underlayed with $|\gamma|$, representing the deviation of the contours between stream function and bottom topography. For $|\gamma|>0.9$ the deviation angle between the isolines of the stream function and the isobath is less than $25^{\circ}$. Contour interval is $0.2 \times 10^{5} \mathrm{~m}^{3} \mathrm{~s}^{-1}$.

Tellus 54A (2002), 3 

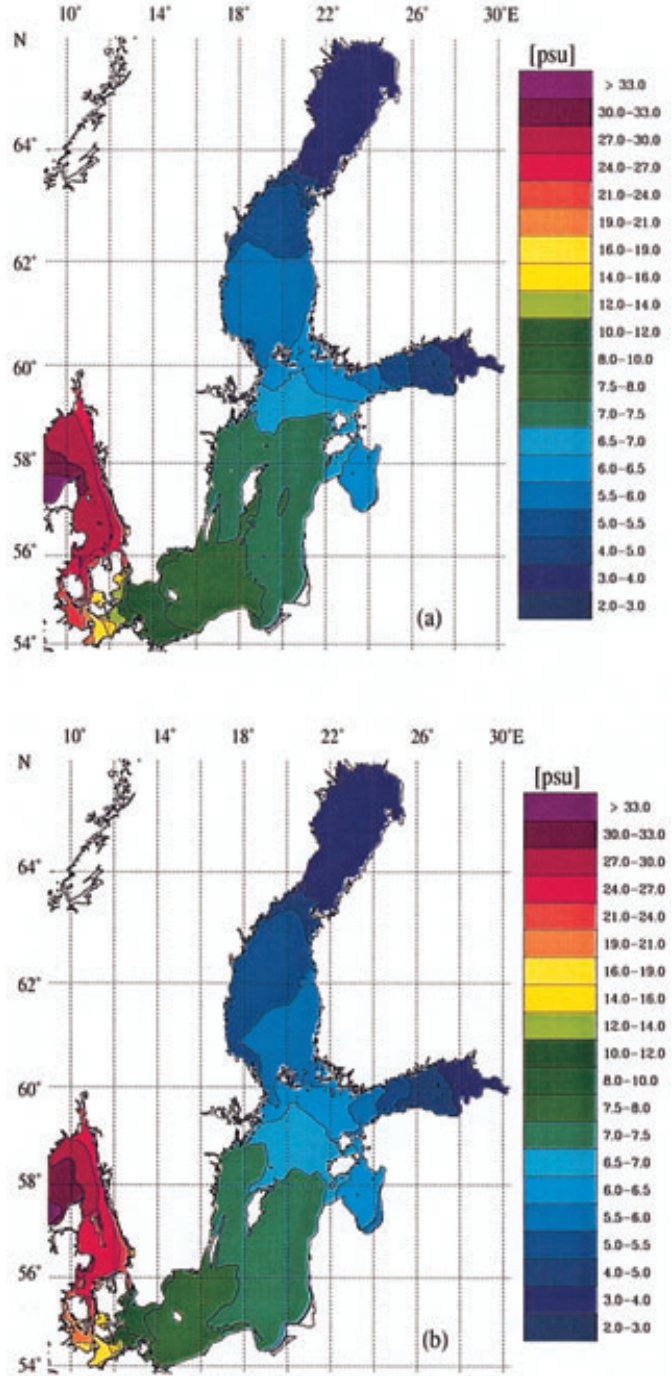

Fig. 6. Ten-year average 1986-1995 of the sea surface salinity distribution ( $\mathrm{psu}$ ) (vertical average of the upper $24 \mathrm{~m}$ ) for (a) March and (b) July.

over the first eight model levels, corresponding to a depth range of 0-24 m) is displayed for March and July. In the Skagerrak, observed mean salinity distributions (Rodhe, 1996) are well reproduced by the model. Among others, Rodhe (1996) investigated the dynamics of the large-scale circulation in the Skagerrak. He concluded that the mean cyclonic circulation in the Skagerrak is to a large extent forced by the mixing of highly saline deep water into the outflowing low-salinity surface water of Baltic origin. The mean transport of the cyclonic circulation in the Skagerrak, which extends from the sea surface to the bottom down to at least $400-500 \mathrm{~m}$, has been estimated to be somewhere between $0.5 \times 10^{6}$ and $1.0 \times 10^{6} \mathrm{~m}^{3} \mathrm{~s}^{-1}$. Short-term temporal changes of the transport in the basic circulation are of the same magnitude as the mean. Occasionally, there is a reversal of the horizontal circulation (Rodhe, 1996). From the 10-yr average (Fig. 5), the cyclonic transport in the Skagerrak is about $1.2 \times 10^{5} \mathrm{~m}^{3} \mathrm{~s}^{-1}$. The simulated transport is of the right order, although considerably smaller than the observed transport. However, our estimation is based on a $10-\mathrm{yr}$ average, and the maximum model depth of the Skagerrak is only $255 \mathrm{~m}$. Thus, we do not resolve the full depth range of the Skagerrak with the maximum depth close to $700 \mathrm{~m}$.

In the central Baltic Sea, the mean horizontal salinity distribution (Fig. 6) can be compared with observations presented in Eilola and Stigebrandt (1998; Fig. 7). From the seasonal variation of the horizontal salinity distribution, Eilola and Stigebrandt (1998) determined the spreading of juvenile freshwater (Gustafsson and Stigebrandt, 1996) in the Baltic proper. They concluded that the spreading of juvenile freshwater is controlled

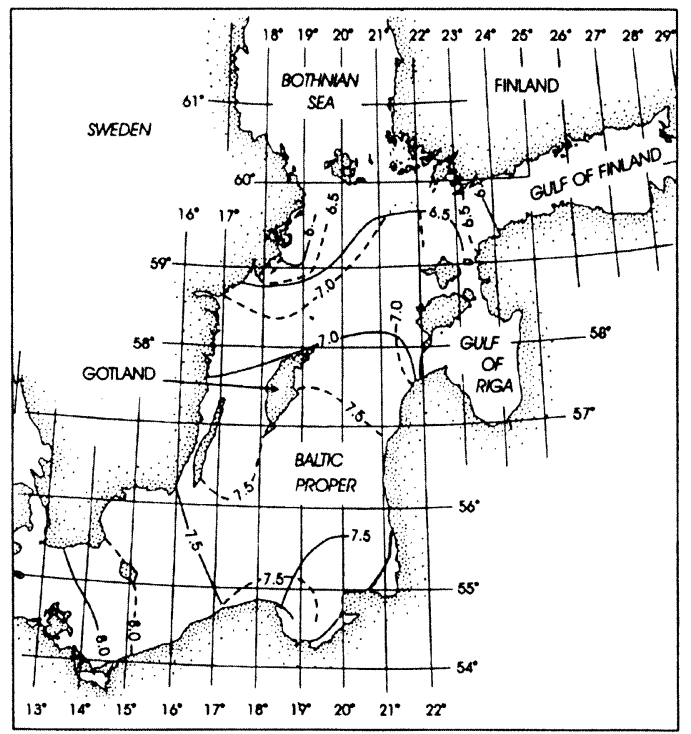

Fig. 7. Mean salinity in the upper $25 \mathrm{~m}$ of the Baltic proper in March (dashed line) and July (solid line) by courtesy of Eilola and Stigebrandt (1998). 
by unsteady motions induced by fluctuating winds, and to a minor extent by the mean weak cyclonic circulation with mean surface velocities of 0-0.04 $\mathrm{m} \mathrm{s}^{-1}$ (Kullenberg, 1981; Sjöberg, 1992). Furthermore, corresponding geostrophic surface transports, which were calculated through vertical cross-sections of $1^{\circ} \times 25 \mathrm{~m}$, range from 0 to $0.7 \times 10^{5} \mathrm{~m}^{3} \mathrm{~s}^{-1}$. The geostrophic transports were too weak to explain the observed southward transports of juvenile freshwater. Furthermore, Eilola and Stigebrandt (1998) stated, if the circulation of a three-dimensional circulation model is in error, erroneous surface salinities will result.

The 10-yr average of the salinity distribution as well as the seasonal variation are well reproduced by the model (Fig. 6). The corresponding mean surface velocities for the upper $24 \mathrm{~m}$ of the water column are in the range $0.02-0.08 \mathrm{~m} \mathrm{~s}^{-1}$, where the higher velocities are concentrated in flow bands of about $50 \mathrm{~km}$ width. In the deep area of the eastern Gotland Basin, maximum velocities of about $0.1 \mathrm{~m} \mathrm{~s}^{-1}$ are found. The simulated surface velocities seem to be considerably higher than the observed weak cyclonic circulation. However, for specific months the averaged surface velocities are considerably smaller (e.g. $0.01-0.04 \mathrm{~m} \mathrm{~s}^{-1}$ for July). The simulated flow bands circulate a huge amount of water within the Baltic proper. The corresponding transport is between $1 \times 10^{5}$ and $1.5 \times 10^{5} \mathrm{~m}^{3} \mathrm{~s}^{-1}$ (Fig. 5).

Outside the up- and downwelling regions, the circulation in the deep basins of the Baltic Sea is due to an interplay of earth rotation and depth variations on timescales of $f^{-1}$ and longer. The general nature of the circulation can be described by a depth integrated vorticity balance, derived from the transport equation for variable depth with bottom friction neglected (e.g. Csanady, 1982).

$$
\begin{aligned}
\frac{\partial \zeta}{\partial t}-\frac{f}{H} \frac{\partial \eta}{\partial t}= & -\frac{g}{H}\left(\frac{\partial H}{\partial x} \frac{\partial \eta}{\partial t}-\frac{\partial H}{\partial y} \frac{\partial \eta}{\partial x}\right) \\
& +\frac{1}{\rho H} \nabla \times \vec{\tau}, \quad \zeta=\frac{\partial V}{\partial x}-\frac{\partial U}{\partial y}
\end{aligned}
$$

where $\zeta$ is the vorticity of the baroptropic flow, $H$ is the water depth and $\eta$ is the sea surface elevation. The curl of the wind stress $(\nabla \times \vec{\tau})$ can be neglected on the basin scale, and for barotropic geostrophic currents

$U_{\mathrm{g}}=-\frac{g}{f} \frac{\partial \eta}{\partial y}, \quad V_{\mathrm{g}}=\frac{g}{f} \frac{\partial \eta}{\partial x}$

the vorticity tendency reduces to

$\frac{\partial \zeta}{\partial t}=\frac{f}{H} \frac{\partial \eta}{\partial t}+\frac{f}{H} \vec{U}_{\mathrm{g}} \cdot \nabla H$.

Thus, vorticity is generated through vortex stretching due solely to the rise and fall of the sea surface, and/or by depth variations, i.e if the geostrophic flow crosses depth contours. For the temporal average, under the assumption of a steady state, it follows

$\vec{U}_{\mathrm{g}} \cdot \nabla H=\nabla \psi \cdot \nabla H=0$

On the long-term average, the geostrophic barotropic flow is parallel to the depth contours, i.e. the isolines of the stream function $(\psi)$ correspond to the isobaths of the bottom topography,

$\gamma=\cos \alpha=\frac{\nabla \psi \cdot \nabla H}{|\nabla \psi| \nabla H \mid}$.

In Fig. 5, the mean transport stream function for the period 1986-1996 is plotted. In regions of $|\gamma|>0.9$, the contours of $\psi$ and $H$ deviate by less than $25^{\circ}$. Especially in the deep basins, the resulting circulation is associated with the steepening of the bottom slope in the direction of the flow (cf. also with Fig. 1). We use the mean circulation as reference for variations in the circulation of the Baltic Sea for $\mathrm{NAO}^{+}$and $\mathrm{NAO}^{-}$ conditions.

\section{Changes in circulation and upwelling for $\mathrm{NAO}^{+}$and $\mathrm{NAO}^{-}$phases}

To demonstrate the changes in circulation and upwelling in the Baltic Sea, we chose JFM 1987 as a representative for $\mathrm{NAO}^{-}$and JFM 1989 for $\mathrm{NAO}^{+}$conditions. The circulation patterns obtained for the remaining years of the ensembles are similar with respect to the corresponding NAO phases. However, the strength of the circulation depends on ice coverage and the intensity of the atmospheric conditions described by either the BSI and/or the NAO. The winter 1986/87 was a severe winter, with the Baltic Sea almost totally frozen (Haapala and Leppäranta, 1996), and correspondingly the NAO as well as the BSI remained 
in negative phase. The winter $1988 / 89$ was a mild winter, with ice only in the most northern and eastern parts of the Baltic Sea, and with a local maximum in the NAO and BSI. The 3-month average (JFM 1987) of the anomalous SLP field of the Baltic region was determined by a high pressure cell, situated over Scandinavia, leading to easterly winds over the western Baltic Sea and the Kattegat/Skagerrak area with mean geostrophic wind speeds of about $5 \mathrm{~m} \mathrm{~s}^{-1}$. In JFM 1989, the averaged anomalous SLP field revealed a meridional pressure gradient strongest between northern Scandinavia and the eastern part of Germany, leading to westerly winds of about $7.6 \mathrm{~m} \mathrm{~s}^{-1}$. These contrary atmospheric conditions led to contrary volume exchanges between the Baltic Sea and the North Sea. The calculated anomalies of volume exchange for JFM 1987 and JFM 1989 amount to -27 and $281 \mathrm{~km}^{3}$, respectively. To estimate the total volume exchange, the anomalies of volume change due to the atmospheric forcing must be supplemented by the volume change resulting from the river runoff, and the net effect of precipitation minus evaporation, which is approximately $11600 \mathrm{~m}^{3} \mathrm{~s}^{-1}$ (Lehmann and Hinrichsen, 2000a). During outflow conditions, for a 3-month period about $100 \mathrm{~km}^{3}$ will additionally flow out of the Baltic Sea; during inflow, this volume will be stored and later released.

The impact of the different forcing conditions on the circulation of the Baltic Sea is depicted in Figs. 8 to 11. The surface flow fields for JFM 1987 and JFM 1989 are represented by streamlines giving only information about the directional characteristics without the variations in the intensity. Additionally, the stability of the flow, which is defined as the ratio of the averaged vectorial velocity and the averaged arithmetic velocity (Neumann and Pierson, 1967; Lehmann and Hinrichsen, 2000b), is underlayed. The strength of the circulation patterns in the Baltic Sea can be deduced by the stream function representations from Figs. 5, 9 and 11. Due to reversed wind conditions for the years 1987 and 1989, there is a shift or even a reversal of distinct circulation patterns.

At the surface (Fig. 8), the circulation for JFM 1987 is rather similar to the barotropic flow (Fig. 9). High stabilities in the Gulf of Bothnia and the Gulf of Finland are due to sea ice coverage. Sea ice modifies the momentum flux from the atmosphere to the ocean. For high sea ice concentrations, the ice will become immobile, and

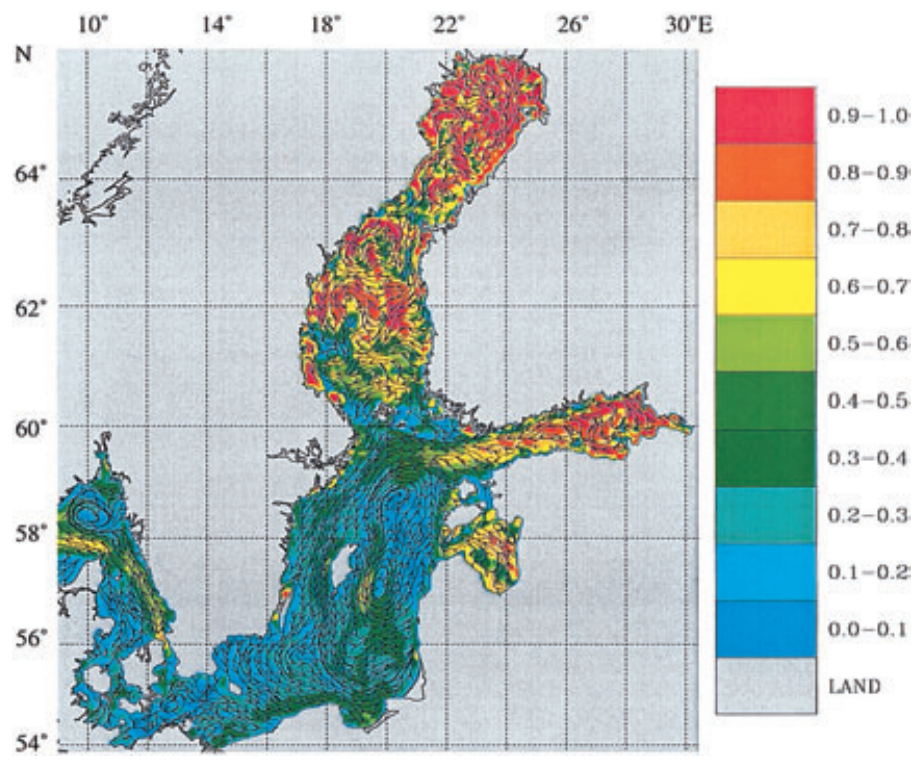

Fig. 8. Streamlines representation of the average of the surface velocity for January, February and March 1989 , underlayed with the stability of the surface flow. Colour bar represents stability values $0-1$. 


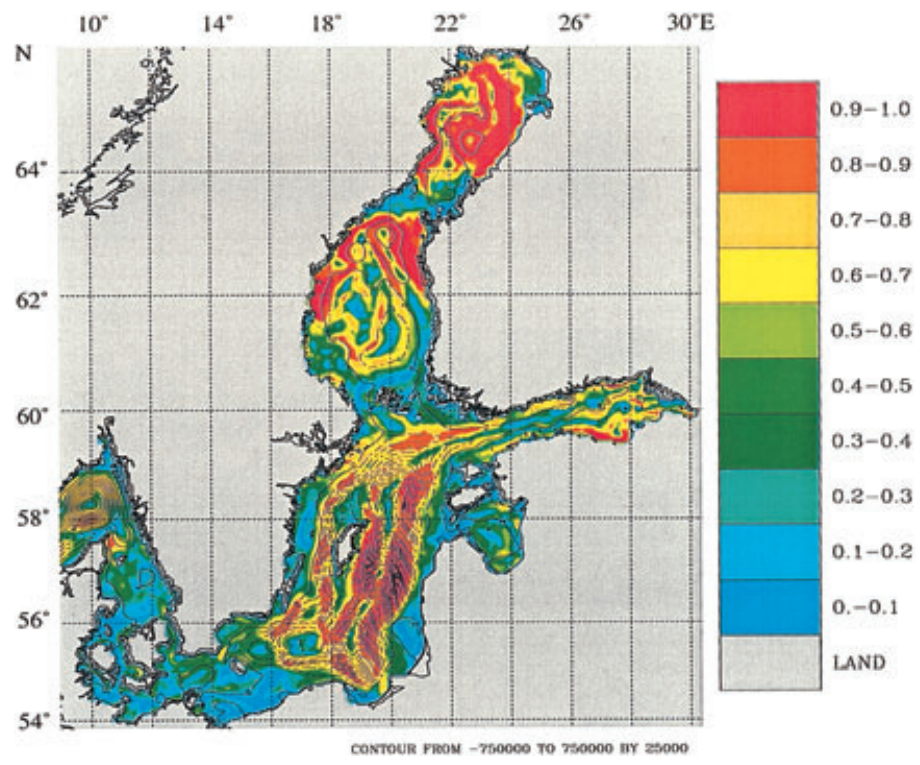

Fig. 9. Stream function representation of the average of the barotropic circulation for January, February and March 1989 , underlayed with the stability of the barotropic flow. Colour bar represents stability values $0-1$. Contour interval is $0.25 \times 10^{5} \mathrm{~m}^{3} \mathrm{~s}^{-1}$.

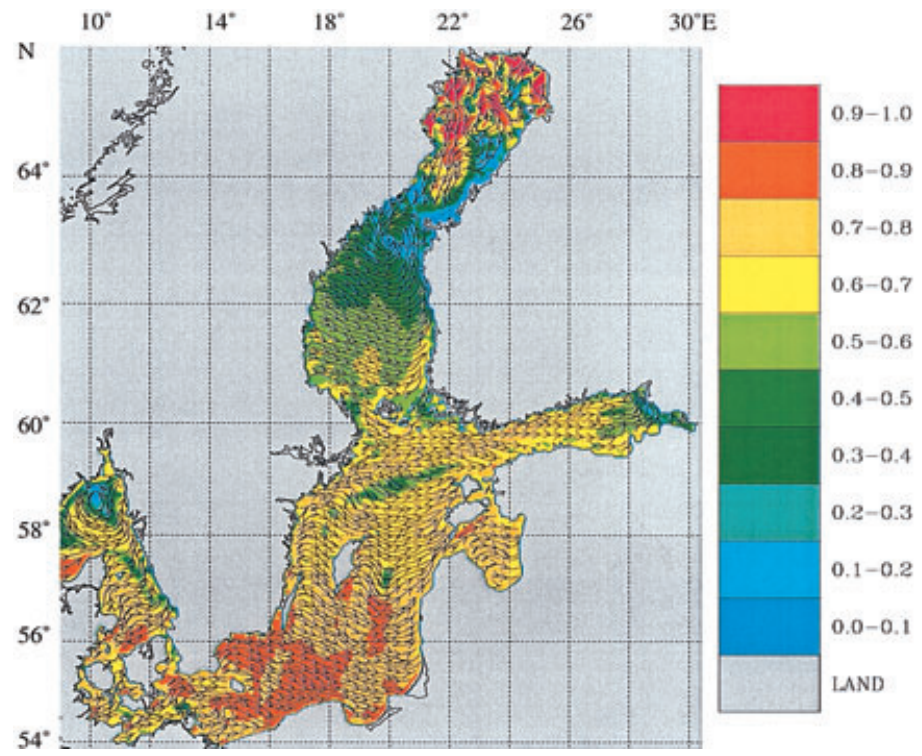

Fig. 10. Streamlines representation of the average of the surface velocity for January, February and March 1987, underlayed with the stability of the surface flow. Colour bar represents stability values $0-1$.

insulates the ocean from the atmospheric wind stress. Due to frictional effects, the lower sea ice surface constitutes a momentum sink for the surface ocean currents. Low stabilities in the central
Baltic, the western Baltic Sea and the Kattegat/ Skagerrak account for the variability in the atmospheric forcing, also apparent in the corresponding BSI values (Fig. 2). The barotropic circulation

Tellus 54A (2002), 3 


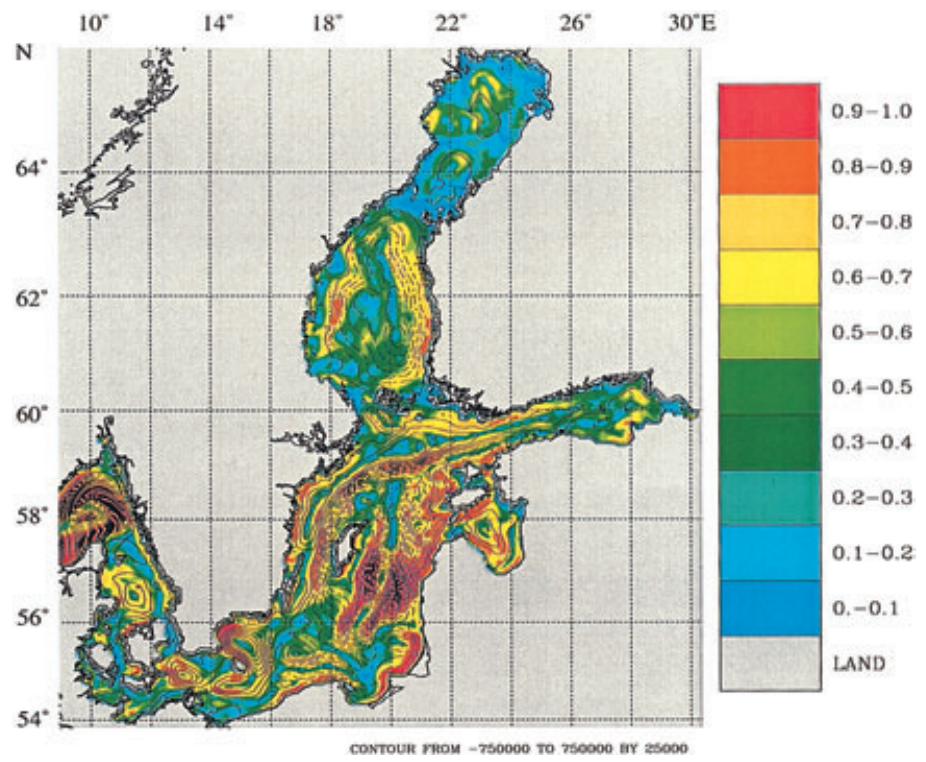

Fig. 11. Stream function representation of the average of the barotropic circulation for January, February and March 1987, underlayed with the stability of the barotropic flow. Colour bar represents stability values $0-1$. Contour interval is $0.25 \times 10^{5} \mathrm{~m}^{3} \mathrm{~s}^{-1}$.

(Fig. 9) in the Baltic proper is concentrated in persistent current branches, with a pronounced connection of the transport regime of the western Gotland Basin through the Bornholm Basin and the Stolpe Trench into the eastern Gotland Basin. The water volume exchange from west to east through the Stolpe Trench $\left(1.25 \times 10^{5} \mathrm{~m}^{3} \mathrm{~s}^{-1}\right)$ is in contrast to the prevailing easterly wind conditions. The cyclonic circulation in the central Baltic $\left(1.25 \times 10^{5} \mathrm{~m}^{3} \mathrm{~s}^{-1}\right.$ in the western Gotland Basin and $3.25 \times 10^{5} \mathrm{~m}^{3} \mathrm{~s}^{-1}$ in the eastern Gotland Basin) is similar to the general circulation obtained from the 10-yr average (Fig. 5), but, strongly increased due to the forcing conditions. There are strong deviations from the general circulation in the Skagerrak and the Bothnian Sea. In the Skagerrak, the rotational sense is reversed and the transport is increased to about $2.5 \times 10^{5} \mathrm{~m}^{3} \mathrm{~s}^{-1}$. In the Bothnian Sea, the cyclonic circulation has been broken up into smaller cyclonic and anticylonic circulation cells.

The circulation for JFM 1989 shows strong differences to JFM 1987. Due to the strong westerly wind conditions, the averaged surface current field exhibits for most parts of the Baltic Sea an almost horizontally homogeneous Ekman drift to the east (Fig. 10). The surface flow is rather stable, with stabilities for most parts of the Baltic Sea in the range 0.7-0.8. Where the Ekman drift is directed to/off the coast a convergence/divergence is established, with the consequence of rising/falling sea level in order to conserve mass. Furthermore, the inclination of the sea level near the coasts is accompanied by up- and downwelling, resulting in a baroclinic response confined to a distance from the coast of the internal Rossby radius. Consequently, geostrophically balanced coastal jets directed mainly in the wind direction are produced. Such coastal jets are apparent along both coasts of the Bornholm and Gotland Basin, also partly in the Gulf of Finland with a return flow in the central parts of the basins (Fig. 11). Note the reversed circulation in the Skagerrak $\left(6.25 \times 10^{5} \mathrm{~m}^{3} \mathrm{~s}^{-1}\right)$, Arkona and Bornholm Basin and the Gulf of Riga compared to JFM 1987 (Fig. 9). The Kattegat gyre is pronounced and shifted to the west. Through the Stolpe Trench $\left(1.25 \times 10^{5} \mathrm{~m}^{3} \mathrm{~s}^{-1}\right)$, the flow is directed to the west in contrast to the surface flow which is directed to the east. The circulation in the Baltic Proper has been spun off by the strong forcing for the western branch to $1.75 \times 10^{5} \mathrm{~m}^{3} \mathrm{~s}^{-1}$, and 
$4.25 \times 10^{5} \mathrm{~m}^{3} \mathrm{~s}^{-1}$ in the circulation cell comprising the deep eastern Gotland Basin. Compared to the general circulation (Fig. 5), the correspondence between the circulation patterns in the sub-basin is higher for JFM 1989 than for JFM 1987. The highest deviations of the JFM 1989 circulation from the general circulation occur in the areas of the Skagerrak, the Bornholm Basin and the Stolpe Trench.

Corresponding to the strong changes in the horizontal circulation, the vertical velocity reverses its sign for the up- and downwelling regime directly influenced by the wind (Fig. 12). Extreme values of vertically averaged vertical velocities for the years 1987 (about $\pm 5 \times 10^{-6} \mathrm{~m} \mathrm{~s}^{-1}$ ) and 1989 (about $\pm 5 \times 10^{-5} \mathrm{~m} \mathrm{~s}^{-1}$ ) are found along the coasts, also reversed in direction. For a stratified ocean, up- and downwelling areas forced by the wind-driven Ekman transport are confined to a distance from the coast of the internal Rossby radius, which is about $5 \mathrm{~km}$ in the Baltic Sea (Fennel, 1991). The zone affected by the up- and downwelling is about twice this distance (Fig. 12). This is in accordance with observations of upwelling areas in the Baltic Sea derived from satellite data (Gidhagen, 1987). From the analyis of the satellite data, horizontal scales of the coastal upwelling were found to be of the order of $100 \mathrm{~km}$ alongshore, and some $10-20 \mathrm{~km}$ offshore. Additionally, the dynamically forced up- and downwelling due to the gyre circulation are also affected where the horizontal circulation changes its sense of rotation. Vertical velocities are strongly enhanced for the $\mathrm{NAO}^{+}$phase compared to the $\mathrm{NAO}^{-}$conditions, which is mainly a result of the stability of the horizontal flow and, indeed, of the prevailing atmospheric conditions.

\section{Summary and conclusions}

The water mass exchange between the Baltic Sea and the North Sea in response to atmospheric forcing and freshwater surplus is well understood.
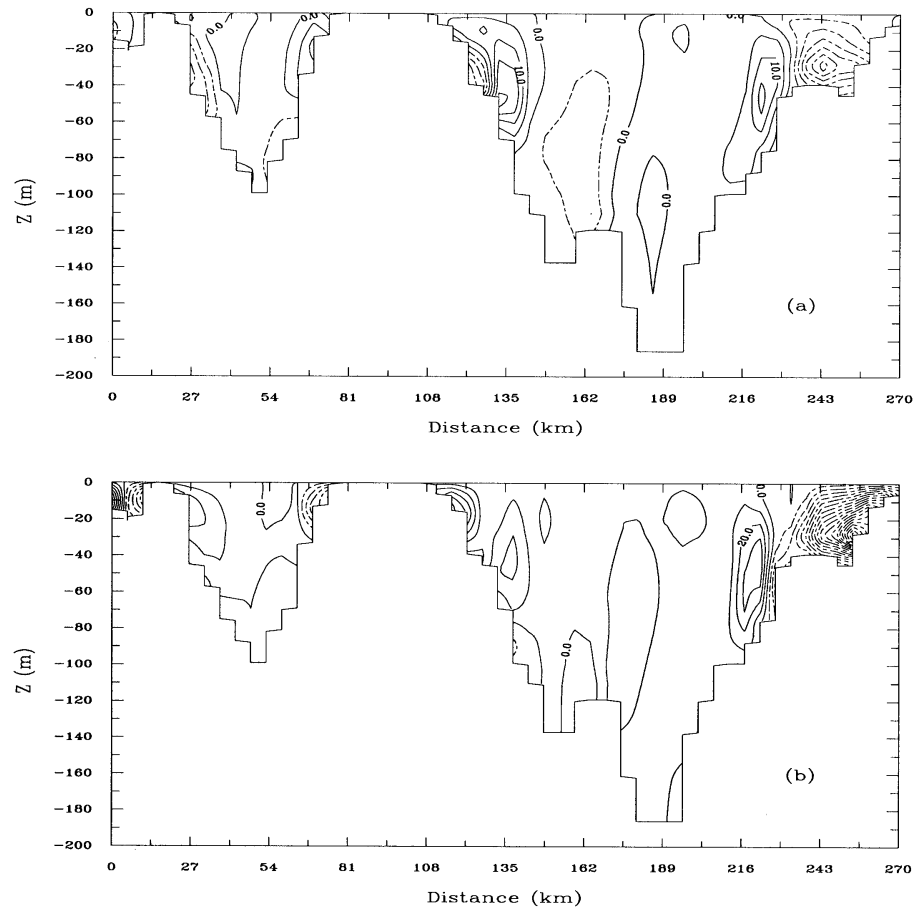

Fig. 12. Section of averaged vertical velocity $\left(10^{-6} \mathrm{~m} \mathrm{~s}^{-1}\right)$ along $57^{\circ} \mathrm{N} 15^{\prime}$ for January, February and March 1987 (a) and January, February and March 1989 (b). Full line represents upwelling, broken line downwelling. Contour interval is (a) $5 \times 10^{-6} \mathrm{~m} \mathrm{~s}^{-1}$ and (b) $10 \times 10^{-6} \mathrm{~m} \mathrm{~s}^{-1}$.

Tellus 54A (2002), 3 
However, less is known about the three-dimensional circulation of the Baltic Sea. In this work, changes in circulation and upwelling in the Baltic Sea have been studied from numerical model simulations. Three-dimensional models have reached a sufficient state of accuracy that a coherent picture of the circulation of the entire Baltic Sea and its variabilities can be described. The main findings of the work can be summarized as follows.

To relate the local atmospheric conditions over the western Baltic Sea to the water mass exchange and the corresponding mean sea level variations, an index has been introduced which is defined as the difference between normalised sea level pressures at Oslo and Szczecin. A positive BSI provides inflow conditions, and negative BSI values are correlated with outflow and a corresponding drop of the mean sea level. The BSI is clearly related to the NAO. About $25 \%$ of the local atmospheric variance can be accounted for by the influence of the NAO. However, the correlation between the NAO and the volume exchange or mean sea level elevation of the Baltic Sea is small. This indicates that a possible influence of the NAO on the Baltic Sea must first become evident in the local atmospheric conditions, which constitute the direct impact.

The detrended net volume exchange through the Danish Sounds is almost perfectly correlated with the sea surface elevation at Landsort. Furthermore, the volume exchange is clearly related to the BSI. Thus, the sea level observations provide a long-term record for changes in the inand outflow regime of the Baltic Sea. Any climate change concerning the BSI and also a large-scale atmospheric pattern (Ulbrich and Christoph, 1999) should be evident in the long-term record of the sea surface elevation at Landsort.
The mean circulation in the deep basins could be described by a depth integrated vorticity balance, where the strongest circulation is associated with a steepening of the bottom slope in the direction of the flow. With respect to the mean circulation, we showed that different extreme atmospheric situations, where both the NAO and the BSI have a local maximum and minimum, respectively, force different circulation patterns associated with changes in up- and downwelling along the coasts and in the deep basins. Under $\mathrm{NAO}^{+}$and $\mathrm{NAO}^{-}$phases, the Baltic Sea circulation is strongly affected with partly changing the rotational sense of circulation patterns. Consequently, the horizontal and vertical advection will be different for different phases of the NAO, implying differences in the turbulent mixing and stratification in the Baltic Sea, with a corresponding impact on the biological processes controlled by advection (Hinrichsen et al., 2001b). Furthermore, due to Ekman transport away from the coast, deep water is required to upwell to replace the surface water which has been removed. As the deep water contains nutrients which will be brought up into the euphotic zone, any changes in the prevailing wind conditions will have an impact on the primary production and probably also on the dynamics of higher trophic levels.

\section{Acknowlegements}

We are grateful to Barry Broman (SMHI), who provided the Landsort tide gauge data, and Larss Meuller (SMHI), who provided the atmospheric forcing data. We also thank an anomymous reviewer who helped to improve the paper by a number of constructive comments. The work was supported by the BMBF (German Ministry for Education and Research, 01 LA 9814/9).

\section{REFERENCES}

Bergström, S. and Carlsson, B. 1994. River runoff to the Baltic Sea: 1950-1990. Ambio 23, 280-287.

Csanady, G. T. 1982. Circulation in the coastal ocean. D. Reidel, Dordrecht, The Netherlands. 279 pp.

Dietrich, G. 1951. Oberflächenströmungen im Kattegat, im Sund und in der Beltsee. Deutsche Hydrogr. Z. 4, 129-150.

Dietrich, G. and Schott, F. 1974. Wasserhaushalt und Strömungen. In: Meereskunde der Ostsee (eds.
L. Maagard and G. Rheinheimer), Springer-Verlag Berlin, 33-41.

Eilola, K. and Stigebrandt, A. 1998. Spreading of juvenile freshwater in the Baltic Proper. J. Geophys. Res. 103, C12, 27,795-27,807.

Elken, J. 1996. Circulation modelling. In: Deep water overflow, circulation and vertical exchange in the Baltic proper (ed. J. Elken), Estonian Marine Institute, Tallin, Estonia, Rep. Ser., 6, 91 pp. 
Fennel, W. 1991. Rosby radii and phase speeds in the Baltic Sea. Cont. Shelf Res. 11, 23-36.

Gidhagen, L. 1987. Coastal upwelling in the Baltic Sea. Satellite and in situ measurements of sea surface temperatures indicating coastal upwelling. Estuarine, Coastal and Shelf Sci. 24, 449-462.

Gustafsson, B. 1997. Interaction between Baltic Sea and North Sea. Germ. J. Hydrogr. 49, 165-183.

Gustafsson, B. and Stigebrandt, A. 1996. Dynamics of the freshwater-influenced surface layers in the Skagerrak. J. Sea Res. 35, 39-53.

Haapala, J. and Leppäranta, M. 1996. Simulating the Baltic Sea ice season with a coupled ice-ocean model, Tellus 48A, 622-643.

Hänninen, J., Vuorinen, I. and Hjelt, P. 2000. Climatic factors in the Atlantic control the oceanographic an ecological changes in the Baltic Sea. Limnol. Oceanogr. 45, 703-710.

Hagedorn, R., Lehmann, A. and Jacob, D. 2000. A coupled high resolution atmosphere-ocean model for the BALTEX region. Meteor. Z. 1, 1-14.

Harder, M., 1996. Dynamik, Rauhigkeit und Alter des Meereises in der Arktis -Numerische Untersuchungen mit einem grobskaligen Modell, Ber. zur Polarforsch. 203, Alfred-Wegener-Institut für Polar- und Meeresforschung, Bremerhaven, Germany.

HELCOM, 1986. Baltic Marine Environment Protection Commission - Helsinki Commission, 1986, Baltic Sea Environment Proceedings No.16, Helsinki, Finland, $174 \mathrm{pp}$.

Hibler, W. D. 1979. A dynamic thermodynamic sea ice model. J. Phys. Oceanogr. 9, 815-846.

Hilmer, M. and Jung, T. 2000. Evidence for a recent change in the link between the North Atlantic Oscillation and Arctic sea ice export. Geophys. Res. Lett. 27, 989-992.

Hinrichsen, H.-H., Lehmann, A., St. John, M. A. and Brügge, B. 1997. Modeling the cod larvae drift in the Bornholm Basin in summer 1994. Cont. Shelf Res. 17, 1765-1784.

Hinrichsen, H.-H., Böttcher, U., Oeberst, R., Voss, R. and Lehmann, A. 2001a. The potential of advective exchange between the western and eastern Baltic cod stock early life stages. Fish. Oceanogr. 10, 249-258.

Hinrichsen, H.-H., St.John, M. A., Aro, E., Gronkjr, P. and Voss, R. 2001b. Testing the larval drift hypothesis in the Baltic Sea: retention vs. dispersion due to the influence of the wind driven circulation. ICES Mar Sci. Symp. 58, 973-984.

Hurrell, J. W. 1995. Decadal trends in the North Atlantic Oscillation regional temperatures and precipitation. Science 269, 676-679.

Hurrell, J. W. 1996. Influence of variations in extratropical wintertime teleconnections on Northern Hemisphere temperature. Geophys. Res. Lett. 23, 665-668.

Hurrell, J. W. and van Loon, H. 1997. Decadal variations in climate associated with the North Atlantic Oscillation. Climate Change 36, 301-326.

Jacobsen, T. S. 1981. The physical oceanography of the open Danish water. In: The Belt Project: evaluation of the physical, chemical and biological measurements (ed. G. Aetebjerg Nielsen), National Agency of Environmental Protection, Denmark, 122 pp.

Kalnay, E., Kanamitsu, M., Kistler, R., Collins, W. Deaven, D., Gandin, L., Iredell, M., Saha, S., White, G., Woollen, J., Zhu, Y., Chelliah, M., Ebisuzaki, W., Higgins, W., Janowiak, J., Mo, K. C., Ropelewski, C., Wang, J., Leetmaa, A., Reynolds, R., Jenne, R. and Joseph, D. 1996. The NCEP/NCAR 40-year reanalysis project. Bull. Am. Meteorol. Soc. 77, 437-470.

Kielmann, J. 1981. Grundlagen und Anwendung eines numerischen Modells der geschichteten Ostsee. Ber. Inst. für Meeresk, Kiel, No. 87a/b, 158/116 pp.

Killworth, P., Stainforth, D., Webbs, D. J., Paterson, S. M. 1989. A free surface Bryan-Cox-Semtner model. Inst. Oceanogr. Sci. Deacon Lab. Rep., No. 270, 184 pp. Killworth, P., Stainforth, D., Webbs, D. J. and Paterson, S. M. 1991. The development of a free-surface BryanCox-Semtner ocean model. J. Phys. Oceanogr. 21, 1333-1348.

Koslowsky, G. and Loewe, P. 1994. The western Baltic Sea ice season in term of mass related severity index 1879-1992. Part I: temporal variability and association with the North Atlantic Oscillation. Tellus 46A, 66-74.

Koslowsky, G. and Glaser, R. 1999. Variations in reconstructed ice winter severity in the western Baltic from 1501 to 1995 , and their implications for the North Atlantic Oscillation. Climate Change 41, 175-191.

Kullenberg, G. 1981. Physical oceanography. In: The Baltic Sea. (ed. A. Voipo) Elsevier Oceanogr. Ser. 30, 135-182.

Lass, H. U. and Matthäus, W. 1996. On temporal wind variations forcing salt water inflows into the Baltic Sea. Tellus 48A, 663-671.

Lass, H. U. and Schwabe, R. 1990. An analysis of the salt water inflow into the Baltic in 1975 to 1976. Dt. Hydrogr. Z. 43, 97-125.

Lehmann, A. 1995. A three-dimensional baroclinic eddyresolving model of the Baltic Sea. Tellus 47A, 1013-1031.

Lehmann, A. and Hinrichsen, H.-H. 2000a. On the thermohaline variability of the Baltic Sea. J. Mar. Sys. 25, 333-357.

Lehmann, A. and Hinrichsen, H.-H. 2000b. On the wind driven and thermohaline circulation of the Baltic Sea. Phys. Chem. Earth, B 25, 183-189.

Lehmann, A. and Hinrichsen, H.-H. 2001. The importance of water storage variations for water balance studies of the Baltic Sea. Phys. Chem. Earth, B 26, (5-6), 383-389.

Lisitzin, E. 1974. Sea-level changes. Elsevier Oceanogr. Ser. 8, 286.

Matthäus, W. and Schinke, H. 1994. Mean atmospheric circulation patterns associated with Major Baltic Inflows. Dt. hydrogr. Z. 46, 321-338.

Meier, H. E. M. 1999. First results of multi-year simula-

Tellus 54A (2002), 3 
tions using a 3D Baltic Sea model. Rep. Oceanogr. 27, SMHI, S-60176 Norrköping, Sweden, 48 pp.

Meier, H. E. M. 2000. The use of a $k-\varepsilon$ turbulence model within the Rossby Centre regional ocean climate model: Parameterization, development and results. Rep. Oceanogr. 28, SMHI, S-60176 Norrköping, Sweden, 81 pp. Sea model. Reports Oceanogr. 27, SMHI, S-60176 Norrköping, Sweden, 48 pp.

Neumann, G. and Pierson, W. J. 1967. Principles of physical oceanography. Prentice-Hall Int., London, $545 \mathrm{pp}$.

Omstedt, A. and Chen, D. 2001. Influence of atmospheric circulation on the maximum ice extent in the Baltic Sea. J. Geophys. Res. 106, 4493-4500.

Omstedt, A., Meuller, L. and Nyberg, L. 1997. Interannual, seasonal and regional variations of precipitation and evaporation over the Baltic Sea. Ambio 26 , 484-492.

Osborn, T. J., Briffa, K. R., Tett, S. F. B. and Jones, P. D. 1999. Evaluation of the North Atlantic Oscillation as simulated by a coupled climate model. Clim. Dyam. 15, 685-702.

Parkinson, C. L. and Washington, W. M. 1979. A largescale numerical model of sea ice. J. Geophys. Res. 84, 311-337.

Planque, B. and Taylor, A. H. 1998. Long-term changes in plankton and the climate of the North Atlantic. ICES J. Mar. Sci. 78, 1015-1018.

Rogers, J. C. 1984. The association between the North Atlantic Oscillation and the Southern Oscillation in the Northern Hemisphere. Mon. Weather Rev. 112 1999-2015.

Rodhe, J. 1996. On the dynamics of the large-scale circulation of the Skagerrak. J. Sea Res. 35, 9-21.
Samuelsson, M. and Stigebrandt, A. 1996. Main characteristics of the long-term sea level variability in the Baltic Sea. Tellus 48A, 672-683.

Sarkisyan, A. S., Staskwiecz, A. and Koalik, Z. 1975. Diagnostic computations of the summer circulation in the Baltic Sea. Oceanologica 15, 653-656

Schinke, H. and Matthäus, W. 1998. On the causes of major Baltic inflows an analysis of long time series. Cont. Shelf Res. 18, 67-97.

Schrum, C. and Backhaus, J. O. 1999. Sensitivity of atmosphere-ocean heat exchange and heat content in North and Baltic Sea. A comparative assessment. Tellus 51 A, 526-549.

Simons, T. J. 1978. Wind-driven circulations in the southwest Baltic. Tellus 30, 272-283.

Sjöberg, B. 1992. Sea and coast, national atlas of Sweden, SMHI Norrköping. SNA Publishing, 128 pp.

Stigebrandt, A. 1983. A model for the exchange of water and salt between Baltic and the Skagerrak. J. Phys. Oceanogr. 13, 411-427.

Stössel, A. and Owens, W. B. 1992. The Hamburg sea-ice model. DKRZ Techn. Rep. No. 3.

Ulbrich, U. and Christoph, M. 1999. A shift of the NAO and increasing storm track activity over Europe due to anthropagenic green house gas forcing. Clim. Dynam. 15, 551-559.

Voss, R., Hinrichsen, H.-H. and St.John, M. A. 1999. Variations in the drift of larval cod (Gadus morhua L.) in the Baltic Sea: combining field observations and modeling. Fish. Oceanogr. 8, 199-211.

Zorita, E. and Laine, A. 2000. Dependence of salinity and oxygen concentrations in the Baltic Sea on largescale atmospheric circulation. Clim. Res. 14, 25-41. 